\title{
Using X-ray-computed Tomography to Nondestructively Determine Maturity of Green Tomatoes
}

\author{
Jeffrey K. Brecht ${ }^{1}$ \\ Vegetable Crops Department, Institute of Food and Agricultural \\ Sciences, University of Florida, Gainesville, FL 32611 \begin{abstract}
University of Georgia Agricultural Experiment Station, Griffin, GA 30223
\end{abstract} \\ Robert L. Shewfelt ${ }^{2}$, Joseph C. Garner ${ }^{3}$, and E.W. Tollner ${ }^{4}$
}

Additional index words. CT scan, imaging, Lycopersicon esculentum, fruit maturity, X-ray CT

\begin{abstract}
Cross-sectional X-ray-computed tomography (X-ray CT) images through the equator of tomato fruit (Lycopersicon esculentum Mill., CV. Sunny) ranging in maturity from immature (MI) to advanced mature green (M4) revealed localized differences in X-ray absorption related to the formation of locular gel during maturation of the fruit. While maturity stage was poorly correlated with average X-ray absorbance and standard deviation or with average fruit density and water content, significant relationships' existed between maturity stage "and the number of image pixels with absorbance values >10 (Ml vs. M2 vs. M3) or 20 (M3 vs. M4) Hounsfield units. Using discriminant analysis, a relationship was developed that correctly identified the maturity class of $77 \%$ of the fruit and placed $96 \%$ of the tomatoes into the correct or an adjacent class.
\end{abstract}

Proper maturity at harvest is a critical factor in determining the quality of tomato fruit picked green. The U.S. Standards for grades of fresh tomatoes, recognizing the relationship between maturity and the ability of the fruit to ripen properly, defines maturity using the internal indicators of gel formation in the locules and seed development (U.S. Dept. Agr., 1976). Little difference in sensory quality was observed in ripened tomato fruit harvested at mature-green and breaker stages (Kavanaugh et al., 1986; Resurreccion and Shewfelt, 1985; Watada and Aulenbach, 1979). Immature fruit, however, may fail to ripen or take an unacceptably long time to ripen (Brecht, 1987; Kader et al., 1977), exhibit increased susceptibility to chilling injury (Autio and Bramlage, 1986; Thompson et al., 1964), and also may be more susceptible to surface injuries and water loss (Kader and Morris, 1976a) than mature fruit. Use of locular gel formation and seed development as criteria for tomato maturity, however, normally requires destruction of the fruit. Inability to distinguish between physiological substages of green fruit has obscured the results of sensory quality studies (Watada and

Received for publication 20 Dec. 1989. Florida AgriculturalExperimentStationsJournalSeriesno.

R-00945. The cost of publishing this paper was defrayed in part by the payment of page charges. Underpostal regulations, this paper therefore must be hereby marked advertisement solely to indicate this fact.

'Associate Professor.

${ }^{2}$ Associate Professor, Food Science Dept.

${ }^{3}$ ResearchEngineer,AgriculturalEngineeringDept.

${ }^{4}$ Associate Professor, Agricultural Engineering Dept.
Aulenbach, 1979) and of modeling color development during ripening of tomatoes (Shewfelt et al., 1988).

External factors associated with tomato fruit maturity include shape, color, surface appearance, and stem scar condition (Kader and Morris, 1976b). Use of these external indicators of maturity is partly subjective; thus, their usefulness, especially in commercial harvesting or sorting operations, is questionable. In practice, green tomatoes are harvested and sorted based on legal minimum size requirements, such as those in effect in Florida (Florida Tomato Committee, 1989). This practice can result in varying amounts of immature fruits being packed and shipped.

Studies of the effect of fruit maturity on the postharvest physiology of tomato are green). Far left: M4 (advanced mature-green). similarly affected by lack of convenient indicators of maturity. The most common procedures used to obtain green tomatoes of known maturity are to tag the flowers at anthesis and harvest the fruit at known times (Lyons and Pratt, 1964) or to retroactively group fruit based on the number of days from harvest to the. first appearance of red surface color (Kader et al., 1977). The former procedure is usually not feasible when many fruit are needed and the latter procedure is useless when the treatment being investigated affects the ripening rate.

Maturity-sorting of green tomatoes using light transmittance was reported by Worthington et al. (1976). However, green tomatoes are optically very dense and the researchers were unable to measure light transmittance in $>60 \%$ of the freshly harvested fruit. Nattuvetty and Chen (1980) used a fiber optic attachment to measure light transmittance through a small region of tomato fruit. Their ability to sort tomatoes into maturity classes was variable among maturity classes and cultivars, probably due to variability in internal fruit morphology and the small area of the fruit measured.

$\mathrm{X}$-ray transmittance has been used to measure maturity of lettuce (Lenker and Adrian, 1971), bruising in apples (Diener et al., 1970), and hollow heart in potatoes (Finney and Norris, 1973). Differences in X-ray transmittance are related to the density of the tissue being tested. The image resulting from conventional X-ray transmittance measurement is an average of the X-ray absorption values through the whole thickness of the tissue.

$\mathrm{X}$-ray computed tomography (X-ray CT) uses a movable X-ray source and detector assembly to accumulate data from a thin projected "slice" of the sample material (a CT scan). From the accumulated data, X-ray absorption values (Hounsfield units) are calculated for each pixel within the scanned region. Air is defined as having a Hounsfield unit value of -500 and water a value of 0 . The pixel absorption values are the basis for a two-dimensional image of the scanned region (Tollner et al., 1989). $\mathrm{X}$-ray CT images display extremely high res-

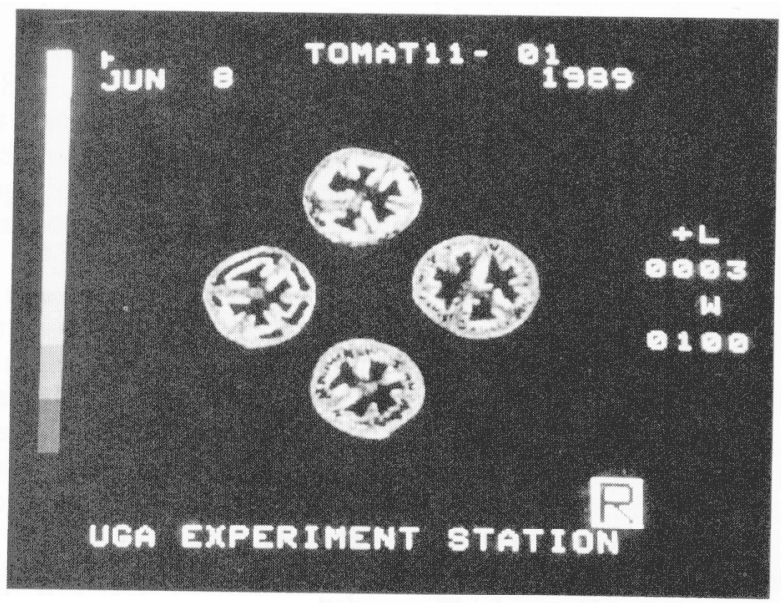

Fig. 1. X-ray CT images of green 'Sunny' tomato fruits representing the four maturity classes used in this study. Far right: M 1 (immature). Below: M2 (partially mature). Above: M3 (typical mature- 
Table 1. Comparison of actual maturity class (determined by visual evaluation of sliced fruit) and predicted maturity class (determined by visual elevation of on-screen X-ray CT images as shown in Fig. 1). ${ }^{2}$

\begin{tabular}{lcrrr}
\hline \hline $\begin{array}{l}\text { Actual } \\
\text { maturity } \\
\text { class }\end{array}$ & \multicolumn{4}{c}{ Predicted maturity class } \\
\cline { 2 - 5 } & M1 & M2 & M3/M4 & Total \\
\hline M1 & 7 & 4 & 1 & 12 \\
M2 & 2 & 4 & 6 & 12 \\
M3 & 0 & 0 & 12 & 12 \\
M4 & 0 & 5 & 7 & 12 \\
Total & 9 & 13 & 26 & 48 \\
\hline
\end{tabular}

Twelve fruit per maturity class were preselected as described in Materials and Methods section. X-ray CT screen images were used to predict maturity class based on the presence of bright areas corresponding to locule gel; no attempt was made to distinguish between the M3 and M4 maturity classes.

Table 2. Comparison of actual maturity class (determined by visual evaluation of sliced fruit) and predicted maturity class (determined by discriminant analysis).

\begin{tabular}{lcrcrr}
\hline \hline $\begin{array}{l}\text { Actual } \\
\text { maturity } \\
\text { class }\end{array}$ & \multicolumn{5}{c}{ Predicted maturity class } \\
\cline { 2 - 6 } & M 1 & M2 & M3 & M4 & Total \\
\hline M1 & 11 & 1 & 0 & 0 & 12 \\
M2 & 4 & 7 & 1 & 0 & 12 \\
M3 & 0 & 2 & 9 & 1 & 12 \\
M4 & 0 & 2 & 0 & 10 & 12 \\
Total & 15 & 12 & 10 & 11 & 48 \\
\hline
\end{tabular}

${ }^{2}$ Twelve fruit per maturity class were preselected as described in Materials and Methods section and scanned using X-ray CT. Discriminant analysis (SAS, 1985) was used to predict maturity class based on total Hounsfield units and number of pixels with absorbance values $>0,10$, and 20 Hounsfield units in X-ray CT images.

olution compared to conventional X-ray transmittance images. While X-ray CT has been widely adopted in medicine, its use in agriculture has so far been limited. Equipment expense and unfamiliarity with CT scanning concepts best explain the limited application of CX in agriculture to date (Tollner et al., 1987).

The cell walls of the locular tissue in tomato undergo autolysis during development to produce the typical jelly-like tissue found in mature fruits (acting and Gregosy, 1963). This autolysis, or gel formation, is temporally correlated with the appearance of autocatalytic ethylene production in the tissue and the initiation of ripening (Brecht, 1987; Jones et al., 1989). Intercellular air spaces comprise $\approx 10 \%$ of the volume of the pericarp tissue and the locular tissue before gel formation (J. K. B., unpublished). After autolysis, the locular tissue is completely liquid. Our objective was to evaluate whether $\mathrm{X}$-ray CT could be used to detect the maturity changes in green tomato fruit related to this change in density of the locule tissue during gel formation.

Green 'Sunny' tomatoes were picked from commercial tomato fields in Florida in March and June of 1989 and transported to Griffin, Ga., within 1 day of harvest. Fruit with a diameter range of 63 to $72 \mathrm{~mm}$ were used in this study. An EMI 5005 scanner (Hayes, Middlesex, U. K.) with $120 \mathrm{kV}, 1881 \mathrm{~mA}$-s $\mathrm{X}$-ray intensity, 320-mm scan field diameter and 5-mm collimation (slice thickness) was used to scan the fruit on the day of arrival. Fruit were placed in a wooden holder specially constructed to hold four fruit so that all four could be scanned simultaneously. The fruit were oriented in the holder so that the scanned plane was in the center of the fruit perpendicular to the stem-blossom axis. The fruit were either randomly selected for scanning and then cut in half through the approximate scan plane for visual observation after scanning (March test) or selected before scanning (June test) by cutting each fruit perpendicular to the stem-blossom axis about one-quarter of the distance from each end and 12 fruit each grouped by maturity class based on the appearance of the locule tissue (Kader and Morris, 1976b). The data presented in this paper are from the latter set of fruit. X-ray CT images were monitored on a CRT display. X-ray absorption in Hounsfield units was recorded for each pixel in an image; then pixel histograms were printed for each scanned fruit, enabling rapid deterabsorption thresholds. After scanning, the density and moisture content of each fruit were measured.

Data were analyzed by discriminant analysis (DISCRIM) using the Stastical Analysis System (SAS, 1985). The DISCRIM procedure develops a discriminant function or classification criterion by use of a measure of generalized squared distance and also computes the posterior probability of an observation belonging to each class. Each observation is placed in the class from which it has the smallest generalized squared distance. Number of pixels in an image with absorbance values $>0,10$, and 20 Hounsfield units and the total Hounsfield units for an image were used as variables in the analysis as suggested by examination of pixel histograms.

The presence of gel tissue in the locules of the tomato fruit is indicated by areas of intense signal in X-ray CT images (Fig. 1). The gel tissue in fully mature (M3 or M4) mination of pixel numbers above selected fruit appears as crescent-shaped bright areas. Subjective determination of maturity class by visual evaluation of screen images (Table 1) was difficult for partially mature (M2) fruit since a "missing" or closed locule could cause gel formation to appear only partially complete. Distinguishing M3 from M4 fruit based on examination of screen images was not possible; thus, the two maturity classes were combined (Table 1). Both M3 and M4 fruit have completely autolysed tissue in all locules, but M4 fruit have some internal red coloration (Kader and Morris, 1976b). About $79 \%$ of the fully mature (M3/M4) fruit were correctly classified from the screen images, while only $\approx 58 \%$ of the $\mathrm{Ml}$ and $33 \%$ of the M2 fruit were correctly classified.

There were no significant differences between maturity classes in average fruit X-ray absorbance values or variability of X-ray absorbance values within fruit as indicated by standard deviations of pixel values (data not shown). Average fruit density and water content also were not strongly correlated with fruit maturity. These results probably reflect the discrete nature of the changes that occur in the fruit during maturation.

Within an image, the number of pixels with X-ray absorbance values $>0,10$, or 20 Hounsfield units differed significantly in fruit of different maturities (data not shown). This difference corresponded to the amount of relatively dense tissue in the locules of the fruit. Use of discriminant analysis provided a much cleaner separation of maturity classes than did visual evaluation of on-screen images (cf. Tables 1 and 2). Some difficulty was encountered in distinguishing between $\mathrm{M} 1$ and M2 fruit but discrimination between M3 and M4 fruit was much better using discriminant analysis. The incorrect classification of two M4 fruit as M2 may be attributed to some slight puffiness in the M4 sample (see Fig. 1, far left). This condition would have resulted in less of the relatively dense gel tissue per fruit. About $92 \%$ of the Ml fruit, $58 \%$ of the M2 fruit, $75 \%$ of the M3 fruit, and $83 \%$ of the M4 fruit were correctly classified (Table 2). Overall, $\approx 96 \%$ of the fruit were placed in the corrector an adjacent class.

These results suggest that there is good potential for developing X-ray CT as a nondestructive method for monitoring maturity changes in tomato fruit. A distinct change in the brightness of the locule area in the X-ray CT images was apparent in immature vs. fully mature fruit. However, classification accuracy needs to be improved in order for $\mathrm{X}$ ray $\mathrm{CT}$ to be useful for maturity sorting. Use of percentage of the image area with absorbance values above a cutoff value and of relative rather than absolute absorbance values may help reduce variability due to fruit size and density differences. Work with more fruit from more diverse backgrounds is needed to confirm the potential of this method.

\section{Literature Cited}

Autio, W. R., and W.J. Bramlage. 1986. Chilling sensitivity of tomato fruit in relation to ripening 
and senescence. J. Amer. Soc. Hort. Sci. 111:201-204

Brecht, J.K. 1987. Locular gel formation in developing tomato fruit and the initiation of ethylene production. HortScience 22:476-479.

Cocking, E.C. and D.W. Gregory. 1963. Organized protoplasmic units of the plant cell: I. their occurrence, origin and structure. J. Expt. Bet. 14:504-511.

Diener, R. G., J.P. Mitchell, and M.L. Rhoten. 1970. Using an X-ray image scan to sort bruised apples. Agr. Eng. 51:356-361.

Finney, E.E. and K.H. Norris. 1973. X-ray images of hollow heart potatoes in water. Amer. Potato J. 50:1-8.

Florida Tomato Committee. 1989. Regulatory bulletin no. 1, 1988-89. Annu. Rpt. 1988-1989.

Fla. Tomato Comm., Orlando. p. 9-12.

Jones, R. B., T.M. Wardley, and M.J. Dalling. 1989. Malecular changes involved in the ripening of tomato fruit. J. Plant Physiol. 134:284 289.

Kader, A.A. and L.L. Morris. 1976a. Appearance factors other than color and their contribution to quality. Proc. 2nd Tomato Quality Workshop. Univ. of California, Davis. p. 8-15.

Kader, A.A. and L.L. Morris. 1976b. Correlating subjective and objective measurements of maturation and ripeness of tomatoes. Proc. 2nd Tomato Quality Workshop. Univ. of California, Davis. p. 57-62.

Kader, A. A., M.A. Stevens, M. Albright-Holton, L.L. Morris, and M. Algazi. 1977. Effect of fruit ripeness when picked on flavor and composition in fresh market tomatoes. J. Amer. Soc. Hort. Sci. 102:724-731.

Kavanagh, E. E., W.B. McGlasson and R.L. McBride. 1986. Harvest maturity and acceptability of Flora-Dade tomatoes. J. Amer. Sot. Hort. Sci. 111:78-82.

Lenker, D.H. and P.A. Adrian. 1971. Use of Xray for selecting mature lettuce heads. Trans. Amer. Soc. Agr. Eng. 14:894-898.

Lyons, J.M. and H.K. Pratt. 1964. Effect of stage of maturity and ethylene treatment on respiration and ripening of tomato fruits. Proc. Amer. Soc. Hort. Sci. 84:491-500.

Nattuvetty, V.R. and P. Chen. 1980. Maturity sorting of green tomatoes based on light transmittance through regions of the fruit. Trans. Amer. Soc. Agr. Eng. 23:515-518.

Resurreccion, A.V.A. and R.L. Shewfelt. 1985. Relationships between sensory attributes and objective measurements of postharvest quality of tomatoes. J. Food Sci. 50:1242-1245.

SAS. 1985. SAS user's guide: Statistics. version 5 (cd.). SAS Institute, Inc., Cary, N.C.

Shewfelt, R.L., C.N. Thai, and J.W. Davis. 1988. Prediction of changes in color of tomatoes during ripening at different constant temperatures. J. Food Sci. 53:1433-1437.

Thompson, B. D., D.D. Gull, and L.H. Halsey. 1964. Ripening of three varieties of tomatoes as influenced by age of fruit, pre-ripening temperature and position on the plant. Proc. Fla. State Hort. Soc. 77:156-162.

Tollner, E. W., B.P. Verma, and J.M. Cheshire, Jr. 1987. Observing soil-tool interactions and soil organisms using X-ray computer tomography. Trans. Amer. Soc. Agr. Eng. 30:16051610 .

Tollner, E. W., J.W. Davis, and B.P. Verma. 1989. Managing errors with X-ray computed tomography (X-ray CT) when measuring physical properties. Trans. Amer. Soc. Agr. Eng. 32:1090-1096.

U.S. Department of Agriculture. 1976. United States standards for grades of fresh market tomatoes. U.S.
Dept. Agr., Agr. Mktg. Serv., Washington, D.C. Watada, A.E. and B.B. Aulenbach. 1979. Chemical and sensory qualities of fresh market tomatoes. J. Food Sci. 44:1013-1016.

Worthington, J. T., D.R. Massie, and K.H. Nor- ris. 1976. Light transmission technique for predicting ripening time for intact green tomatoes, p. 46-49. In: J.J. Gaffney (cd.). Quality detection in foods. Amer. Soc. Agr. Eng., St. Joseph, Mo. 